RESEARCH PAPER

\title{
Effect of local youth-access regulations on progression to established smoking among youths in Massachusetts
}

\author{
Carey Conley Thomson, William L Hamilton, Michael B Siegel, Lois Biener, Nancy A Rigotti
}

Tobacco Control 2007;16:119-126. doi: 10.1136/tc.2006.018002

See end of article for authors' affiliations

.....................

Correspondence to: Dr N A Rigotti, Tobacco Research and Treatment Center, 50 Staniford Street, 9th Floor, Boston, MA 02114, USA; nrigotti@ partners.org

Received 24 July 2006

Accepted 23 October 2006

\begin{abstract}
Objective: To test whether community-level restrictions on youth access to tobacco (including both ordinances and enforcement) are associated with less smoking initiation or less progression to established smoking among adolescents.

Design: Prospective cohort study of a random sample of adolescents in Massachusetts whose smoking status was assessed by telephone interviews at baseline and 2-year follow-up, and linked to a state-wide database of town-level youth-access ordinances and enforcement practices.

Participants: A random sample of 2623 adolescents aged 12-17 years who lived in 295 towns in Massachusetts in 2001-2 and were followed in 2003-4.

Main outcome measures: The relationship between the strength of local youth access restrictions (including both ordinances and level of enforcement) and (1) never-smokers' smoking initiation rates and (2) experimenters' rate of progression to established smoking was tested in a multilevel analysis that accounted for town-level clustering and adjusted for potential individual, household and town-level confounders.

Results: Over 2 years, $21 \%$ of 1986 never-smokers initiated smoking and $25 \%$ of 518 experimenters became established smokers. The adjusted odds ratio (OR) for smoking initiation was $0.89(95 \% \mathrm{Cl} 0.61$ to 1.31$)$ for strong versus weak youth-access policies and $0.93(95 \% \mathrm{Cl} 0.67$ to 1.29) for medium versus weak policies. The adjusted OR for progression to established smoking among adolescents who had experimented with smoking was $0.79(95 \% \mathrm{Cl} 0.45$ to 1.39$)$ for strong versus weak local smoking restrictions and $0.85(95 \% \mathrm{Cl}$ 0.50 to 1.45 ) for medium versus weak restrictions.

Conclusions: This prospective cohort study found no association between community-level youth-access restrictions and adolescents' rate of smoking initiation or progression to established smoking over 2 years.
\end{abstract}

$\mathrm{N}$ early $90 \%$ of smokers start smoking during adolescence. ${ }^{1}$ Consequently, preventing teenagers from starting to smoke is a public health priority. ${ }^{23}$ To start smoking, adolescents need access to tobacco products. A teenager's first few cigarettes usually come from friends or family members, but, once smoking becomes more established, youths turn to commercial sources of cigarettes (eg, stores and vending machines) to ensure a reliable supply. ${ }^{3-6}$ They are able to do so despite laws in all US states that ban the sale of tobacco to minors, because compliance with these laws is limited. ${ }^{378}$

If youths could be prevented from easily obtaining cigarettes from commercial sources, it is hypothesised that fewer youths would become smokers. ${ }^{3} 8$ Efforts to reduce youth access to tobacco have focused on enforcing bans on tobacco sales to minors in retail stores-the source of most tobacco bought by youths. A complementary strategy bans self-service displays of tobacco products in retail stores. These displays facilitate youth access to tobacco by encouraging shoplifting and by minimising a young person's contact with a salesperson, thereby making it more likely that a sale will occur. ${ }^{38-10}$ Cigarette sales in vending machines have also been targeted because vending machines are more important tobacco sources for younger teens who have more difficulty in buying tobacco in stores. ${ }^{3}$ Effective strategies include banning vending machine sales of cigarettes or limiting vending machines to adults-only locations. Equipping vending machines with locking devices that must be deactivated by a clerk who presumably verifies the purchaser's age has little evidence of efficacy. ${ }^{3}$

Measures to restrict youths' access to tobacco products have been widely advocated since the early 1990s and are now incorporated into global tobacco control efforts. ${ }^{11}$ The World Health Organization's Framework Convention on Tobacco Control includes a provision requiring ratifying nations to adopt and implement laws that prohibit the sale of tobacco to minors. ${ }^{12}$ In the US, the federal Synar amendment has, since 1996, required all states to have and enforce youth-access laws and document a specific level of compliance or risk loss of federal block grant funds. ${ }^{13}$ Many US communities have gone beyond state laws and adopted local ordinances with stronger youth-access provisions. ${ }^{3}{ }^{14}$ In Massachusetts, for example, the number of towns with some form of youth-access regulation increased from 35 (10\%) in 1994 to $244(70 \%)$ in $2000 .^{3}$

Despite the widespread adoption of youth-access restrictions, this approach remains controversial because evidence to support its efficacy in reducing adolescent smoking is

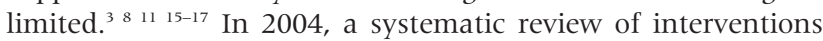
to reduce minors' access to commercial sources of tobacco products was conducted by the Cochrane Tobacco Addiction Group. It concluded that active enforcement of youth-access laws could reduce illegal sales to minors, but found little evidence that these interventions reduced the prevalence of adolescent smoking or perceived ease of access to tobacco products. ${ }^{18}{ }^{19}$ An earlier meta-analysis also found no evidence that increases in merchant compliance with youth-access laws were associated with the prevalence of youth smoking, ${ }^{20}$ although that review's methods were challenged. ${ }^{17}$

Another source of evidence comes from observational studies. These do not test specific interventions but examine the association between adolescent's exposure to youth-access laws or perceived ease of access to tobacco products and their prevalence of smoking. These studies have conflicting results. A cross-sectional study of adolescents in 314 towns in Massachusetts found no consistent association between living

Abbreviation: MTCP, Massachusetts Tobacco-Control Program 
in a town with a youth-access ordinance and prevalence of adolescent smoking or perceived ease of access to tobacco products, but the study had no data on the extent to which merchants actually complied with the laws. ${ }^{21}$ By contrast, a cross-sectional study of 75 communities in Oregon found a small positive linear relationship between a town's measured rate of illegal sales to minors and the prevalence of smoking of 11 th graders, but not of 8 th graders. ${ }^{22} \mathrm{~A}$ cross-sectional analysis of 11 towns in Illinois found that teenagers in towns with higher rates of illegal tobacco sales to minors were more likely to initiate but not to continue to smoke, ${ }^{23}$ However, the cross-sectional design of these studies limits their ability to support causal inferences. Among 12 communities in New York, those reaching a high $(>80 \%)$ rate of retailer compliance with youth-access laws had a smaller increase in adolescents' rate of frequent smoking over 4 years, as measured by two cross-sectional school surveys. ${ }^{24}$

Few observational studies have used the stronger prospective cohort design. A cohort study of 592 adolescent non-smokers in Massachusetts found that those living in towns with a local tobacco sales ordinance at baseline were less likely to progress to established smoking over 4 years than youths in towns without these ordinances. However, the finding lost statistical significance after adjustment for potential confounders and there was no information on actual compliance with the laws. ${ }^{25}$ Gilpin et al ${ }^{26}$ followed two cohorts of adolescent non-smokers in California over 3 years. In the first cohort, followed when merchant compliance with youth access laws was low, smoking initiation rates did not differ between youths who initially perceived that cigarettes were difficult or easy to obtain. In the second cohort, conducted after overall merchant compliance state-wide had improved, youths who perceived that cigarettes were hard to obtain were less likely to initiate smoking.

The current study adds to the existing literature on the effect of youth access restriction in several ways. ${ }^{1}$ It includes data from a representative cohort of adolescents living in a large number of communities that range in size and demographic characteristics. ${ }^{2}$ A town-level clustered multilevel analysis allows us to control for a large variety of individual, environmental and town-level characteristics, including the community's baseline anti-smoking sentiment. ${ }^{3}$ A longitudinal design provides stronger evidence for causal inferences. ${ }^{4}$ The extent to which youth-access laws are actually enforced is measured. ${ }^{5}$ The study deconstructs smoking uptake into two components: youths' experimentation with tobacco products and their progression to established tobacco use. Restrictions on youth-access laws are hypothesised to affect the latter more than the former. ${ }^{38}$

\section{METHODS Study design}

We conducted a 2-year, longitudinal follow-up study of 2504 youths in Massachusetts aged 12-17 years who at baseline had not yet smoked 100 cigarettes. We ascertained the baseline town of residence of each respondent, and using a database of local policies regarding youth access to tobacco products for each of the 351 towns in Massachusetts, determined the strength of the policy in each respondent's town as of the baseline interview date. We examined the relationship between the strength of local youth-access policy and enforcement in a respondent's town at baseline and the likelihood that the respondent initiated smoking or progressed to established smoking over 2 years. Multilevel logistic regression analysis accounted for clustering of responses among youths living in the same town and controlled for potential individual- and town-level confounding factors.

\section{Sample}

Between January 2001 and June 2002, the Center for Survey Research, University of Massachusetts Boston, Massachusetts,
USA, obtained a probability sample of youths in Massachusetts by random digit dialing. Interviewers attempted to interview all resident youths aged 12-17 years in each eligible household identified through an initial screening interview with an adult household resident. Screening interviews were completed for $66 \%$ of sampled households, yielding a sample of 6006 eligible youths. Parental permission was obtained to interview $76 \%$ of eligible youths, and interviews were completed with $84 \%$ of those, resulting in a baseline sample of 3838 adolescents. The number of youths interviewed per household was one for $73.9 \%$ of households, two for $23.3 \%$ and three for $2.7 \%$. Between January 2003 and July 2004, we attempted to re-interview all 3838 of the youths in the baseline sample for whom baseline smoking status had been obtained. Interviews were completed with 2793 subjects, for a follow-up rate of $72.8 \%$.

The research protocol was approved by the institutional review boards of the University of Massachusetts Boston. All subjects gave informed consent or assent (for youths) and a waiver of the requirement for written consent was obtained.

\section{MEASURES}

\section{Town of residence}

A youth's town of residence at baseline and follow-up was determined from the reported zip code. Nearly all (95.8\%) of the re-interviewed youths lived in the same town at baseline and follow-up: 2.5\% moved within Massachusetts and 1.7\% moved out of the state.

\section{Strength of local youth-access policy}

The Massachusetts Tobacco-Control Program (MTCP) maintains a database of tobacco-related policies (including local board of health regulations, municipal ordinances and municipal bylaws) in the state's 351 cities and towns. Data are obtained from reports submitted by local programmes and from queries to towns without programmes and were available for this analysis from 1994 to 2001. The MTCP also collects data on enforcement activities carried out by local boards of health that receive MTCP funding. During the study period, most town health boards received state funding to monitor compliance with the state youth-access law by conducting compliance checks in which supervised minors attempted to buy cigarettes from retailers. These compliance checks could result in fines or licence suspensions if the town had a regulation establishing penalties for selling cigarettes to youth and/or requiring licensure of tobacco vendors. (Among the 102 towns that had fine and/or licensing policies in place and conducted at least two compliance checks per retailer per year, $96 \%$ reported one or more violations, and $83 \%$ of those issued one or more citations, which were the first step in the process of imposing fines or licence suspensions.) Data on the number of compliance checks conducted per tobacco vendor were available for the 2-year period of 1999-2000.

We considered two dimensions of a town's youth-access policy: (1) enforcement of the ban on over-the-counter sales to youths aged $<18$ years and (2) presence of other restrictions on commercial sources of tobacco products to youths. We defined a town as having a strong enforcement policy if two conditions were met. First, regulations requiring licensure of tobacco vendors and/or establishing fines for sales to youth had to be in effect throughout 1999-2000. Second, the local board of health had to have reported an average of at least two compliance checks per vendor per year during that period. ${ }^{\mathrm{i}} \mathrm{A}$ town was considered to have strong restrictions on other commercial

'MTCP guidance suggested that towns conduct compliance checks each calendar quarter, though not necessarily that all vendors should be checked this frequently. About onethird of towns reported averages of two or more compliance checks per vendor per year. 
tobacco sources if it banned free-standing cigarette displays and restricted vending machine sales (with a complete ban, a ban except in adults-only establishments or a lockout device requirement).

The strength of the youth-access policy in each respondent's town of residence was classified as (1) strong if the town met the above criteria for both strong enforcement of restrictions on over-the-counter tobacco sales to minors and strong restrictions on vending machine sales and self-service displays; (2) medium if the town had a strong policy on either of these dimensions; and (3) weak if the town had a strong policy in neither dimension.

\section{Smoking initiation and progression to established smoking}

We considered two potential smoking transitions, depending on respondents' status at baseline. Never-smokers at baseline, who responded negatively to the question "Have you ever experimented with cigarette smoking, even a few puffs?" could remain in that status or could have initiated smoking by followup. Experimenters at baseline-those who had at least puffed but had not smoked 100 cigarettes-could remain in that status or could have smoked 100 cigarettes and become established smokers by follow-up. Established smoking, which captures youths who smoke on a regular basis and avoids the issue of irregular smoking during adolescence and difficulties with recall of smoking behaviour in the past 30 days, has been recognised and used in numerous prior studies. ${ }^{27-32}$ After excluding youths who were already established smokers at baseline, cases with inconsistent responses regarding smoking status and cases with missing values on any of the analysis variables, the final samples included 1986 never-smokers and 518 experimenters located in 295 cities and towns. We considered analysing quitting among established smokers, but there were too few cases (170 established smokers at baseline, of whom 25 were classified as quitters at follow-up) to support analysis of town-level policies.

\section{Potential individual-level and household-level confounding variables}

We controlled for the following individual-level variables assessed at baseline: age, gender, race (non-Hispanic white or other) and rebelliousness. The rebelliousness score was a composite of six agree/disagree items concerning conflict at home and willingness to get into trouble outside the home, which were summed and re-scaled to have values ranging from 0 to $1 .{ }^{33}$ A further control for never-smokers at baseline was a measure of susceptibility to smoking that has previously been shown to predict progression to established smoking. ${ }^{29}$ Neversmokers were classified as non-susceptible to smoking if they answered "no" to the question "Do you think that you will try a cigarette soon?" and "definitely not" to the questions "If one of your best friends were to offer you a cigarette, would you smoke it?" and "At any time during the next year do you think you will smoke a cigarette?" For non-established smokers (youths who had not smoked 100 cigarettes at baseline but who had smoked at least a few puffs), we used indicators for respondents who were current smokers (had smoked in the past 30 days) and for those who had never smoked a whole cigarette.

Household-level control variables were whether any parent smoked, whether the adult survey respondent had any education beyond high school and whether household income was reported to be $\$ 50000$ or more.

\section{Potential town-level confounding variables}

We controlled for the following town-level characteristics: percentage of voters who voted "yes" on question 1 of a 1992 ballot initiative that increased the cigarette tax and created a state-wide tobacco control programme; three levels of town population $(<20000,20000-49999$, and $\geqslant 50000)$; percentage of town population $<18$ years old and percentage of town population that is white. The question 1 vote controls for town norms that existed before local tobacco-control policies were established, as virtually all of the regulations and ordinances first took effect after 1993. Data on the question l vote come from Massachusetts electoral records. ${ }^{34}$ The other town variables come from the 2000 Census.

\section{ANALYSIS}

We estimated separate models of the probability of smoking initiation and the probability of progression to established smoking. In each case, the smoking outcome was treated as a function of the strength of youth-access policy in the respondent's town, controlling for factors that were hypothesised to influence smoking progression but not to be influenced by town policy.

Because individual respondents were clustered within towns and variables were measured at both the respondent and the town levels, we estimated hierarchical models using Hierarchical Linear Modeling V. $6^{35}$ The modelling approach used the full-maximum likelihood estimation of populationaverage models, which is equivalent to the general estimating equations approach. ${ }^{35}$ This approach yields variance estimators that are relatively insensitive to mis-specification of the working correlation matrix. ${ }^{36}$ The results were confirmed by replicating the models using general estimating equations.

In addition to estimating the full model with all variables described above, we estimated reduced models that eliminated variables that did not significantly improve model fit. Change in model fit was assessed using deviance tests, with deviance estimated through LaPlace iterations. To avoid discarding potentially meaningful variables, all variables were retained if the improvement in fit had a $\mathrm{p}$ value of $\geqslant 0.10$.

\section{RESULTS}

Table 1 displays the baseline characteristics and smoking status of the study population. Among the 1986 never-smokers at baseline, $21 \%$ initiated smoking by the follow-up interview, including 3\% who had become established smokers. Among the 518 classified as non-established smokers at baseline, 25\% became established smokers by follow-up. Neither smoking initiation nor becoming an established smoker was significantly related to the strength of youth-access policy in bivariate tests.

Bivariate comparisons show that those who initated smoking between baseline and follow-up were older, more rebellious and more likely to live in a small town. Those who transitioned from non-established to established smokers were more likely to be current smokers at baseline and to live in a town whose population was predominantly white.

Table 2 shows that the local youth-access policy variables were not significantly related to smoking initiation after controlling for potentially confounding factors $(\mathrm{p}=0.655$ and 0.562 for medium and strong policies, respectively). Deviance tests showed that adding these variables did not significantly improve model fit. The reduced model, which is not shown, had point estimates and $\mathrm{p}$ values similar to those in the full model $(\mathrm{p}=0.590$ and 0.520 for medium and strong policies, respectively).

The likelihood of smoking initiation was significantly higher for older youths, those with higher scores on the rebelliousness index, those classified as susceptible to smoking, those with at least one smoking parent and those living in medium-size towns. 
Table 1 Baseline characteristics of the Massachusetts youth cohort, by smoking status at baseline and follow-up*

\begin{tabular}{|c|c|c|c|c|c|c|c|c|}
\hline & \multicolumn{4}{|c|}{ Never-smokers at baseline $(n=1986)$} & \multicolumn{4}{|c|}{ Non-established smokers at baseline $(n=518)$} \\
\hline & \multirow[b]{2}{*}{ All (\%) } & \multicolumn{2}{|c|}{ Status at follow-up } & \multirow[b]{2}{*}{$\mathrm{p}$ Valuet } & \multirow[b]{2}{*}{ All (\%) } & \multicolumn{2}{|c|}{ Status at follow-up } & \multirow[b]{2}{*}{ p Valuet } \\
\hline & & $\begin{array}{l}\text { Never-smoker } \\
\text { (\%) }\end{array}$ & Initiator $(\%)$ & & & $\begin{array}{l}\text { Non- } \\
\text { established } \\
\text { (\%) }\end{array}$ & $\begin{array}{l}\text { Established } \\
(\%)\end{array}$ & \\
\hline \multicolumn{9}{|l|}{ Policy variables } \\
\hline \multicolumn{9}{|l|}{ Strength of youth-access regulations $\ddagger$} \\
\hline Weak & 24.9 & 24.0 & 28.4 & & 28.8 & 26.8 & 34.9 & \\
\hline Medium & 46.5 & 47.2 & 43.6 & & 46.3 & 48.2 & 40.6 & \\
\hline Strong & 28.6 & 28.8 & 28.0 & 0.174 & 24.9 & 25.1 & 24.6 & 0.191 \\
\hline \multicolumn{9}{|l|}{ Individual-level variables } \\
\hline \multicolumn{9}{|l|}{ Age at baseline (years) } \\
\hline $12-14$ & 60.7 & 64.8 & 45.6 & & 29.0 & 27.6 & 33.0 & \\
\hline $15-17$ & 39.3 & 35.2 & 54.4 & 0.000 & 71.0 & 72.4 & 67.0 & 0.255 \\
\hline \multicolumn{9}{|l|}{ Sex } \\
\hline Male & 51.7 & 51.4 & 52.7 & & 49.4 & 47.8 & 53.9 & \\
\hline Female & 48.3 & 48.6 & 47.3 & 0.637 & 50.7 & 52.2 & 46.1 & 0.238 \\
\hline \multicolumn{9}{|l|}{ Race/ethnicity } \\
\hline Non-Hispanic white & 81.9 & 81.2 & 84.4 & & 79.5 & 79.7 & 78.9 & \\
\hline Other & 18.1 & 18.8 & 15.6 & 0.145 & 20.5 & 20.3 & 21.2 & 0.839 \\
\hline \multicolumn{9}{|l|}{ Rebelliousness } \\
\hline Less rebellious (below mean) & 56.9 & 60.6 & 43.2 & & 27.5 & 29.0 & 23.0 & \\
\hline More rebellious & 43.1 & 39.4 & 56.8 & 0.000 & 72.5 & 71.0 & 77.0 & 0.198 \\
\hline \multicolumn{9}{|l|}{ Smoking status at baseline } \\
\hline Non-susceptible non-smoker & 78.3 & 83.0 & 61.2 & & & & & \\
\hline Susceptible non-smoker & 21.7 & 17.0 & 38.8 & 0.000 & & & & \\
\hline Puffer (no whole cigarette) & & & & & 49.3 & 57.4 & 25.3 & \\
\hline $\begin{array}{l}\text { Other experimenter ( } 1-99 \text { cigareftes, } \\
\text { not last } 30 \text { days) }\end{array}$ & & & & & 37.5 & 35.5 & 43.7 & \\
\hline Current smoker (last 30 days) & & & & & 13.2 & 7.2 & 31.0 & 0.000 \\
\hline \multicolumn{9}{|l|}{ Household-level variables } \\
\hline \multirow{2}{*}{\multicolumn{9}{|c|}{ At least one parent smokes }} \\
\hline No & & & & & & & & \\
\hline Yes & 24.2 & 22.5 & 30.6 & 0.001 & 36.4 & 35.3 & 39.5 & 0.409 \\
\hline \multicolumn{9}{|l|}{ Education of adult informant } \\
\hline Not a college graduate & 52.3 & 52.0 & 53.6 & & 63.6 & 64.7 & 60.5 & \\
\hline College graduate & 47.7 & 48.0 & 46.4 & 0.560 & 36.4 & 35.3 & 39.5 & 0.090 \\
\hline \multicolumn{9}{|l|}{ Household income } \\
\hline$\leqslant \$ 50000$ or not reported & 39.5 & 40.0 & 37.9 & & 46.6 & 46.5 & 46.9 & \\
\hline$>\$ 50000$ & 60.5 & 60.0 & 62.1 & 0.454 & 53.4 & 53.5 & 53.1 & 0.948 \\
\hline \multicolumn{9}{|l|}{ Town-level variables } \\
\hline \multicolumn{9}{|l|}{ Town population } \\
\hline$<20000$ & 38.9 & 37.5 & 44.0 & & 38.3 & 36.3 & 44.2 & \\
\hline $20000-50000$ & 36.4 & 37.6 & 32.3 & & 35.1 & 35.6 & 33.8 & \\
\hline$>50000$ & 24.7 & 25.0 & 23.7 & 0.049 & 26.6 & 28.1 & 22.0 & 0.231 \\
\hline $\begin{array}{l}\text { Percentage of town "yes" vote on } \\
\text { question } 1 \text { (mean) }\end{array}$ & 51.0 & 50.9 & 51.3 & 0.331 & 50.7 & 50.5 & 51.4 & 0.304 \\
\hline $\begin{array}{l}\text { Percentage of town residents who are } \\
\text { white (mean) }\end{array}$ & 85.9 & 85.7 & 86.8 & 0.104 & 85.4 & 84.4 & 88.3 & 0.004 \\
\hline $\begin{array}{l}\text { Percentage of town residents who are } \\
\text { aged } 18 \text { years (mean) }\end{array}$ & 24.6 & 24.7 & 24.4 & 0.187 & 24.2 & 24.3 & 24.2 & 0.781 \\
\hline $\begin{array}{l}\text { *Cohort includes only youths who were no } \\
t p \text { Value results from the } \chi^{2} \text { statistic or } F \\
\text { fLocal youth access regulations were clas } \\
\text { compliance checks of two per vendor per y } \\
\text { (2) medium if the town had either strong } \\
\text { restrictions. }\end{array}$ & ed as (1) & $\begin{array}{l}\text { kers (ie, had sm } \\
\text { e-way analysis o } \\
g \text { if the town hac }\end{array}$ & $\begin{array}{l}\text { moked }<100 \\
\text { of variance. } \\
\text { ad strong enf } \\
\text { ctions (restricti } \\
\text { restrictions; a }\end{array}$ & $\begin{array}{l}\text { rcement (re } \\
\text { ons on both } \\
\text { id (3) weak }\end{array}$ & $\begin{array}{l}\text { ir life) at } \\
\text { tions allo } \\
\text {-standing } \\
\text { ee town h }\end{array}$ & $\begin{array}{l}\text { fines or requir } \\
\text { efte displays a } \\
\text { ither strong er }\end{array}$ & $\begin{array}{l}\text { ng licences, ar } \\
\text { d vending ma } \\
\text { forcement nor }\end{array}$ & $\begin{array}{l}\text { d average } \\
\text { thine marketing) } \\
\text { strong marketing }\end{array}$ \\
\hline
\end{tabular}

Table 3 shows that, among youths who had already initiated smoking at baseline, local youth-access policy was not significantly related to the probability of progressing to established smoking by the follow-up interview $(\mathrm{p}=0.545$ and 0.416 for medium and strong policies, respectively). The reduced model, not shown, had similar results $(\mathrm{p}=0.418$ and 0.261 for medium and strong policies, respectively). Significant predictors were age (older youths were less likely to progress), smoking status at baseline (puffers were less likely to progress, current smokers were more likely) and percentage of minority population in the town of residence (youths residing in towns with predominantly white populations were more likely to progress).
Several supplementary analyses (not shown) were conducted to test the robustness of these results. The first analysis added variables representing town restaurant no-smoking regulations, as in Siegel et al. ${ }^{37}$ This did not yield materially different results. When restaurant policy was included, $p$ values for the youth access policy coefficients were slightly larger and odds ratios slightly closer to 1.00. Another set of analyses tested alternative groupings of types of smoking progression. We modelled the probability of being an established smoker at follow-up, conditional only on not being an established smoker at baseline. We also modelled the combined probability of a youth making either of the two types of smoking progression 
Table 2 Adjusted odds ratios for smoking initiation between baseline and follow-up among the Massachusetts youth cohort ${ }^{\star}$

\begin{tabular}{|c|c|c|}
\hline & \multicolumn{2}{|c|}{$\begin{array}{l}\text { Probability that never-smokers at baseline will have } \\
\text { initiated smoking at follow-up }\end{array}$} \\
\hline & OR $(95 \% \mathrm{Cl})$ & $\mathrm{p}$ Value \\
\hline \multicolumn{3}{|l|}{ Policy variables } \\
\hline \multicolumn{3}{|l|}{ Strength of youth-access regulations $\dagger$} \\
\hline Weak & 1.00 & \\
\hline Medium & $0.93(0.671$ to 1.286$)$ & 0.655 \\
\hline Strong & 0.89 (0.610 to 1.308$)$ & 0.562 \\
\hline \multicolumn{3}{|l|}{ Individual-level variables } \\
\hline Age at baseline (continuous) & $1.37(1.271$ to 1.484$)$ & $<0.001$ \\
\hline \multicolumn{3}{|l|}{ Sex } \\
\hline Male & 1.00 & \\
\hline Female & 0.98 (0.789 to 1.222$)$ & 0.871 \\
\hline \multicolumn{3}{|l|}{ Race/ethnicity } \\
\hline Non-hispanic white & $1.07(0.772$ to 1.490$)$ & 0.678 \\
\hline Other & 1.00 & \\
\hline Rebelliousness (continuous) & $3.43(2.020$ to 5.817$)$ & $<0.001$ \\
\hline \multicolumn{3}{|l|}{ Baseline smoking status } \\
\hline Nonsusceptible non-smoker & 1.00 & \\
\hline Susceptible non-smoker & 3.06 (2.275 to 4.107$)$ & $<0.001$ \\
\hline \multicolumn{3}{|l|}{ Household-level variables } \\
\hline \multicolumn{3}{|l|}{ At least one parent smokes } \\
\hline No & 1.00 & \\
\hline Yes & 1.77 (1.298 to 2.420$)$ & 0.001 \\
\hline \multicolumn{3}{|l|}{ Education of adult informant } \\
\hline Not a college graduate & 1.00 & \\
\hline College graduate & $0.95(0.726$ to 1.253$)$ & 0.732 \\
\hline \multicolumn{3}{|l|}{ Household income } \\
\hline$\leqslant \$ 50000$ or unreported & 1.00 & \\
\hline$>\$ 50000$ & $1.15(0.894$ to 1.487$)$ & 0.273 \\
\hline \multicolumn{3}{|l|}{ Town-level variables } \\
\hline \multicolumn{3}{|l|}{ Town population } \\
\hline$<20000$ & 1.00 & \\
\hline $20000-50000$ & $0.73(0.534$ to 1.002$)$ & 0.051 \\
\hline$>50000$ & 0.80 (0.528 to 1.222$)$ & 0.306 \\
\hline $\begin{array}{l}\text { Percentage of town "yes" vote on } \\
\text { question } 1 \text { (continuous) }\end{array}$ & $1.00(0.984$ to 1.015$)$ & 0.937 \\
\hline $\begin{array}{l}\text { Percentage of town residents who are } \\
\text { white (continuous) }\end{array}$ & $1.00(0.992$ to 1.015$)$ & 0.599 \\
\hline $\begin{array}{l}\text { Percentage of town residents who are } \\
\text { aged }<18 \text { years (continuous) }\end{array}$ & $0.97(0.947$ to 1.001$)$ & 0.060 \\
\hline \multicolumn{3}{|c|}{$\begin{array}{l}\text { *Cohort includes only youths who had never smoked or puffed at baseline. } \\
\text { tlocal youth-access regulations were classified as (1) strong if the town had strong enforcement (regulations allowing } \\
\text { fines or requiring licences, and average compliance checks of two per vendor per year) and strong marketing restrictions } \\
\text { (restrictions on both free-standing cigarette displays and vending machine marketing); (2) medium if the town had either } \\
\text { strong enforcement or strong marketing restrictions; and (3) weak if the town had neither strong enforcement nor strong } \\
\text { marketing restrictions. }\end{array}$} \\
\hline
\end{tabular}

examined separately here (from never-smoker to having initiated, and from non-established smoker to established smoker). None of these analyses showed statistically significant effects of the youth-access policy variable at or approaching the 0.05 level.

Finally, we considered alternative configurations of the youth-access policy measure, treating it as a dichotomous (medium or strong vs weak) or continuous variable. We also decomposed the youth access policy index into its component pieces, separately testing policies establishing fines or licensing requirements; having conducted two or more compliance checks per vendor per year; presence of any vending machine regulation; and bans on free-standing displays. In no case was the presence of a particular policy significantly associated with a lower likelihood of smoking initiation or progression. It is therefore unlikely that the overall result is driven by weak measurement of any one policy or a chance concentration of confounding factors in the towns adopting any one policy.

\section{DISCUSSION}

In this longitudinal study of a cohort of Massachusetts adolescents, those living in towns with strong youth-access policies did not have significantly lower rates of smoking initiation or progression to established smoking over a 2-year follow-up, than those living in towns with weak or no policies. A strong policy was defined to require a combination of policies enforcing the prohibition on tobacco sales to youth aged $<18$ years and policies restricting cigarette availability through vending machines or free-standing displays. Neither this combination of policies nor any of the component policies showed statistically significant associations with youth smoking.

We had hypothesised that local youth-access policies might influence youth smoking behaviour both directly and indirectly. Since youth-access policies do influence retailers' actions, ${ }^{18}{ }^{19}$ youths who wish to buy cigarettes should find it more difficult to do so in towns with strong policies. This should impede youths' progression from experimentation to established smoking although it might not affect smoking initiation rates, because youths usually do not obtain their first cigarette from a commercial source. ${ }^{38}$ The more indirect hypothesis is that youths will perceive strong policies and the resultant retailer actions as indicating that smoking is contrary to the social norm, and research suggests that youth smoking behaviour is sensitive to perceived norms. ${ }^{38}$ An effect on perceived norms 
Table 3 Adjusted odds ratios for progression from non-established to established smoking between baseline and follow-up among the Massachusetts youth cohort ${ }^{*}$

\begin{tabular}{|c|c|c|}
\hline & \multicolumn{2}{|c|}{$\begin{array}{l}\text { Probability that non-established smokers at baseline will } \\
\text { have become established smokers at follow-up }\end{array}$} \\
\hline & OR $(95 \% \mathrm{Cl})$ & $\mathrm{p}$ Value \\
\hline \multicolumn{3}{|l|}{ Policy variables } \\
\hline \multicolumn{3}{|l|}{ Strength of youth-access regulations $\dagger$} \\
\hline Weak & 1.00 & \\
\hline Medium & 0.85 (0.499 to 1.445$)$ & 0.545 \\
\hline Strong & 0.79 (0.450 to 1.392$)$ & 0.416 \\
\hline \multicolumn{3}{|l|}{ Individual level variables } \\
\hline Age at baseline (continuous) & $0.82(0.693$ to 0.960$)$ & 0.015 \\
\hline \multicolumn{3}{|l|}{ Sex } \\
\hline Male & 1.00 & \\
\hline Female & $0.67(0.427$ to 1.052$)$ & 0.082 \\
\hline \multicolumn{3}{|l|}{ Race/ethnicity } \\
\hline Non-Hispanic white & 0.61 (0.308 to 1.193$)$ & 0.148 \\
\hline Other & 1.00 & \\
\hline Rebelliousness (continuous) & 1.60 (0.659 to 3.893$)$ & 0.299 \\
\hline \multicolumn{3}{|l|}{ Smoking status } \\
\hline Puffer (no whole cigarette) & 0.33 (0.195 to 0.547$)$ & $<0.001$ \\
\hline Other experimenter (1-99 cigarettes) & 1.00 & \\
\hline \multirow{2}{*}{\multicolumn{3}{|c|}{ Household-level }} \\
\hline & & \\
\hline \multicolumn{3}{|l|}{ At least one parent smokes } \\
\hline No & 1.00 & \\
\hline Yes & 1.13 (0.712 to 1.792$)$ & 0.603 \\
\hline \multicolumn{3}{|l|}{ Education of adult informant } \\
\hline Not a college graduate & 1.00 & \\
\hline College graduate & 0.71 (0.455 to 1.112$)$ & 0.135 \\
\hline \multicolumn{3}{|l|}{ Household income } \\
\hline$\leqslant \$ 50000$ or not reported & 1.00 & \\
\hline$>\$ 50000$ & 1.02 (0.629 to 1.647$)$ & 0.943 \\
\hline \multicolumn{3}{|l|}{ Town-level variables } \\
\hline \multicolumn{3}{|l|}{ Town population } \\
\hline$<20000$ & 1.00 & \\
\hline $20000-50000$ & 0.81 (0.483 to 1.352 ) & 0.417 \\
\hline$>50000$ & 1.07 (0.522 to 2.194$)$ & 0.853 \\
\hline $\begin{array}{l}\text { Percentage of town "yes" vote on } \\
\text { question } 1 \text { (continuous) }\end{array}$ & $1.01(0.981$ to 1.033$)$ & 0.607 \\
\hline $\begin{array}{l}\text { Percentage of town residents who are } \\
\text { white (continuous) }\end{array}$ & $1.03(1.008$ to 1.047$)$ & 0.006 \\
\hline $\begin{array}{l}\text { Percentage of town residents who are } \\
\text { aged }<18 \text { years (continuous) }\end{array}$ & $1.00(0.946$ to 1.064$)$ & 0.918 \\
\hline \multicolumn{3}{|c|}{$\begin{array}{l}\text { *Cohort includes only youths who had smoked but were not established smokers (ie, had not smoked } 100 \text { cigarettes) at } \\
\text { baseline. } \\
\text { †Strength of local youth-access regulations were classified as (1) strong if the town had strong enforcement (regulstions } \\
\text { allowing fines or requiring licences, and average compliance checks of two per vendor per year) and strong marketing } \\
\text { restrictions (restrictions on both free-standing cigarefte displays and vending machine marketing); (2) medium if the town } \\
\text { had either strong enforcement or strong marketing restrictions; and (3) weak if the town had neither strong enforcement } \\
\text { nor strong marketing restrictions. }\end{array}$} \\
\hline
\end{tabular}

might deter smoking initiation, progression to established smoking, or both.

Although we did not find local policies to be significantly associated with initiation or with progression to established smoking, we cannot exclude the possibility that study limitations contributed to the lack of effect. The study was conducted in Massachusetts, where an unusually strong state-level tobacco-control campaign has been operating since $1993 . .^{39} 40$ The state-level efforts, which included extensive media campaigns and tobacco excise tax increases, as well as support for community-level tobacco control, may have swamped differences that would otherwise result from local youth-access policy.

Sample size might also be a factor. Our point estimates are consistent with a reduction in smoking uptake, especially in progression to established smoking, and it is possible that a study with a larger number of towns or a larger number of youth would find effects of this magnitude to be statistically significant. Countering this argument is the fact that Siegel et al ${ }^{37}$ using these same data, found that a strong smoking policy in a local restaurant was significantly associated with a decreased likelihood that youth would become established smokers between baseline and follow-up. We similarly found a significant effect of restaurant policy when we added these measures to our model of progression to established smoking. This combination of results raises the possibility that youth smoking behaviour may respond more sensitively to restaurant policy, which is not targeted to youth, than to the policies specifically targeted to youth access. Two considerations make this seeming contradiction more plausible. First, it is possible that few youths beyond those who actually attempt to buy cigarettes become aware of the retailer actions that are subject to youth-access policy, while many more youth become aware of "no-smoking" signs and the absence of smoking in restaurants. Second, youth-access restrictions may convey the normative statement that smoking is disapproved among youth, but not among adults, whereas the restaurant policy may convey a more powerful statement that smoking is disapproved regardless of age.

Another study limitation concerns the possibility that even the strong local policies in Massachusetts were not strong enough to achieve the hypothesised result. It has been 


\section{What this paper adds}

What is already known on this subject

- Despite the widespread adoption of laws to restrict youths' access to tobacco products, this policy remains controversial because evidence to support its efficacy in reducing adolescent smoking is limited.

- Data from a well-controlled cohort study of adolescents living in communities that differ in youth-access policies and enforcement could inform the debate.

suggested that as long as a few vendors will sell to youth, access regulations will not shut off the supply of cigarettes. ${ }^{41}$ In previous research, reductions in youth smoking have generally required frequent compliance checks and penalties for noncompliance that together achieved high levels $(>80-90 \%)$ of retailer compliance, embedded in comprehensive communitybased interventions. ${ }^{184241}$ The threshold frequency of compliance checks used here to identify towns with strong regulations was less than that achieved in those prior studies. We cannot rule out the possibility that youth-access policies and enforcement that achieve high compliance can reduce youth smoking, but reaching this level of compliance would require a level of resources and community involvement greater than was observed in Massachusetts, which had one of the nation's most proactive and well-funded tobacco-control programmes during the period of this study. ${ }^{39}$ The state assisted local communities in establishing youth-access ordinances and regulations. The state also provided guidelines regarding the frequency and procedures for compliance checks, and required the programmes to keep detailed records of the characteristics of compliance checkers (eg, age and sex) as well as results of the tests. Programme data show that compliance checks resulting in violations were often followed by citations, which was the first step towards imposing a fine or suspending a licence. Programme data have also shown that Massachusetts had high levels of retailer compliance in this period. ${ }^{40}$ Whether stronger enforcement than that in Massachusetts could realistically be expected in an operational setting is unclear. Still, if stronger enforcement could be achieved, it might yield more visible effects than we observed.

Another limitation is that our measure of the strength of youth-access provisions is less comprehensive than has been used in some other studies. Our measures of the presence of regulations and levels of enforcement come from programme operations databases, rather than data collected by researchers. Therefore, we were limited in what data were available, and some measurement error is probably present. We believe, however, that the consistency of results across multiple measures and multiple modelling approaches minimises the possibility that measurement error seriously distorts the findings.

Community-level ordinances are not the only tobaccocontrol efforts that may affect youth smoking initiation. Tobacco education programmes in schools and other tobaccocontrol policies may also affect youths' perceptions and smoking behaviours. ${ }^{215}$ We were able to minimise the potential confounding effect of these factors by conducting this study in a single state, thereby minimising differences between communities in tobacco price, tobacco-control expenditure and counter-advertising media campaigns. When analyses controlled for community-level differences in clean indoor air restrictions in restaurants, there was no change in our findings about the strength of youth-access laws and enforcement.

\section{What this study adds}

- This prospective study assessed the smoking behaviour of 2623 randomly sampled adolescents laged 1217 years) who lived in 295 towns in Massachusetts with varying youth-access laws and enforcement practices.

- Over 2 years, there was no association between community-level youth-access restrictions and adolescents' rate of smoking initiation or progression to established smoking in an analysis that accounted for town-level clustering and adjusted for potential individual, household and town-level confounders.

- The level of youth-access restriction that was achievable in a state with a strong tobacco-control programme was insufficient to demonstrate an independent effect of this policy on adolescent smoking behaviour.

\section{CONCLUSION}

This study of a cohort of Massachusetts adolescents who were followed for 2 years found no significant association between community-level youth-access regulations and adolescents' initiation of smoking or progression to established smoking.

\section{ACKNOWLEDGEMENTS}

This study was funded by the National Cancer Institute's State and Community Tobacco Control Interventions Research Grant Program (\#R01 CA86257), the National Heart Lung and Blood Institute's Midcareer Investigator Award in Patient Oriented Research (\#K2404440), and the Flight Attendant Medical Research Institute (FAMRI). We are grateful to Yevgeniya Kaganova for assistance in the data analyses.

\section{Authors' affiliations}

Carey Conley Thomson, Nancy A Rigotti, From the Tobacco Research and Treatment Center, Massachusetts General Hospital, Boston, Massachusetts, USA; Harvard Medical School, Boston, Massachusetts, USA

Carey Conley Thomson, Department of Medicine, Mount Auburn Hospital Cambridge, Massachusetts, USA; Harvard Medical School, Boston, Massachusetts, USA

William L Hamilton, CNU Associates, Lincoln, Massachusetts, USA

Michael B Siegel, Social and Behavioral Sciences Department, Boston University School of Public Health, Boston, Massachusetts, USA

Lois Biener, Center for Survey Research, University of Massachusetts Boston all in Boston, Massachusetts, USA

Competing interests: None declared.

\section{REFERENCES}

1 CDC. Youth risk behavior surveillance-United States, 2003. MMWR Surveill Summ 2004;53:1-96.

2 US Department of Health and Human Services. State and local legislative action to reduce tobacco use, Monograph number 11. Bethesda, MD: Public Health Service, National Institutes of Health, National Cancer Institute, NIH Publication Number 00-4804, 2000

3 Rigotti NA. Reducing the supply of tobacco in youths. In: Rabin RL, Sugarman SD, eds. Regulating tobacco. New York: Oxford University Press, 2001:143-75.

4 Emery L, Gilpin EA, White MM, et al. How adolescents get their cigarettes: implications for policies on access and price. J Natl Cancer Inst 1999;91:184-6.

5 Castrucci BC, Gerlach KK, Kaufman NJ, et al. Adolescents' acquisition of cigarettes through noncommercial sources. J Adolesc Health 2002;31:322-6.

6 Difranza JR, Coleman M. Sources of tobacco for youth in communities with strong enforcement of youth access laws. Tob Control 2001;10:323-8.

7 State Cancer Legislative Database Program. Tobacco use laws. Bethesda, MD: National Cancer Institute, 2002.

8 Forster JL, Wolfson M. Youth access to tobacco: policies and politics. Annu Rev Public Health 1998; 19:203-35.

9 Cummings KM, Hyland A, Saunders-Martin T, et al. What retailers are doing to prevent tobacco sales to minors. Int Q Community Health Educ, 1998-99, 18:1999-2008. 
10 Tobacco Retailer Responsibility Initiative. Preventing teenage access to tobacco. A Report to the National Association of Attorneys General. Waltham, MA: Institute for Health Policy, Heller Graduate School, Brandeis University, 1999.

11 Etter JF. Laws prohibiting the sale of tobacco to minors: impact and adverse consequences. Am J Prev Med 2006;31:47-51.

12 World Health Organization. Framework Convention on Tobacco Control. www.who.int/tobacco/framework (accessed 11 Feb 2007).

13 US Department of Health and Human Services, Food and Drug Administration. Regulations restricting the sale and distribution of cigarettes and smokeless tobacco to protect children and adolescents; final rule. 21 CFR Part 801, et al. Fed Regist 1996;61:44396-5318.

14 Americans for Nonsmoking Rights Foundation. www.no-smoke.org/ orddbase.html (accessed 10 Feb 2007).

15 Lantz PM, Jacobson JD, Warner KE, et al. Investing in youth tobacco control: a review of smoking prevention and control strategies. Tob Control 2000;9:47-63.

16 Ling PM, Landman A, Glantz SA. It is time to abandon youth access tobacco programmes. Tob Control 2002;11:3-6.

17 Difranza JR. Is it time to abandon youth access programmes? Tob Control 2002; 11:282-4

18 Stead LF, Lancaster T. Interventions for preventing tobacco sales to minors Cochrane Database Syst Rev, 2005:(1):CD001497.

19 Stead LF, Lancaster T. A systematic review of interventions for preventing tobacco sales to minors. Tob Control 2000;9:169-76.

20 Fichtenberg CM, Glantz SA. Youth access interventions do not affect youth smoking. Pediatrics 2002;109:1088-92.

21 Thomson CC, Gokhale M, Biener L, et al. Statewide evaluation of youth access ordinances in practice: effects of the implementation of community-level regulations in Massachusetts. J Public Health Manage Pract 2004;10:481-9.

22 Dent C, Biglan A. Relation between access to tobacco and adolescent smoking Tob Control 2004; 13:334-8.

23 Pokorny SB, Jason LA, Schoeny ME. The relation of retail tobacco availability to initiation and continued smoking. J Clin Child Adolesc Psychol 2003:32:193-204.

24 Cummings KM, Hyland A, Perla J, et al. Is the prevalence of youth smoking affected by efforts to increase retailer compliance with a minors' access law? Nicotine Tob Res 2003:5:465-71.

25 Siegel M, Biener L, Rigotti NA. The effect of local tobacco sales laws on adolescent smoking initiation. Prevent Med 1999;29:334-42.
26 Gilpin EA, Lee L, Pierce JP. Does adolescent perception of difficulty in getting cigarettes deter experimentation? Prevent Med 2004;38:485-91.

27 Pierce JP, Choi WS, Gilpin EA, et al. Tobacco industry promotion of cigarettes and adolescent smoking. JAMA 1998;279:511-15.

28 Wellman RJ, DiFranza JR, Savageau JA, et al. Short term patterns of early smoking acquisition. Tob Control 2004; 13:251-7.

29 Pierce JP, Choi WS, Gilpin EA, et al. Validation of susceptibility as a predictor of which adolescents take up smoking in the United States. Health Psychol 1996; 15:355-61

30 Choi WS, Pierce JP, Gilpin EA, et al. Which adolescent experimenters progress to established smoking in the United States? Am J Prev Med 1997; 13:385-91.

31 Pierce JP, Farkas AJ, Evans N, et al. An improved surveillance measure for adolescent smoking? Tob Control 1995;4(Suppl 1):S47-56.

32 Siegel $M$, Biener $\mathrm{L}$. The impact of an antismoking media campaign on progression to established smoking: results of a longitudinal youth study. Am J Public Health 2000;90:380-6.

33 Biener L, Siegel M. Tobacco marketing and adolescent smoking: more support for a causal inference. Am J Public Health 2000;90:407-11.

34 Elections Division. Public Document Number 43. Massachusetts Elections Statistics 1992. Boston, MA: Office of Massachusetts Secretary of State, 1992.

35 Raudenbush SW, Bryk AS, Cheong YF, et al. HLM 6: Hierarchical Linear and Nonlinear Modeling. Lincolnwood, IL: Scientific Software International, 2004.

36 Zeger SL, Liang K-Y, Albert PS. Models for longitudinal data: a generalized estimating equation approach. Biometrics 1988:44:1049-60.

37 Siegel $M$, Albers $A B$, Cheng DM, et al. Effect of local restaurant regulations on progression to established smoking among youths. Tob Control 2005; 12:300-6

38 Hamilton WL, Biener L, Brennan RT. Do strong local tobacco regulations influence perceived smoking norms? Evidence from adult and youth surveys in Massachusetts. (under review).

39 Biener L, Harris JE, Hamilton W. Impact of the Massachusetts Tobacco Control Programme: population based trend analysis. BMJ 2000;321:351-4.

40 Hamilton WL, Rodger CN, Chen X, et al. Independent evaluation of the Massachusetts Tobacco Control Programme. 8th Annual Report: January 1994June 2001, Cambridge, MA:Abt Associates, 2003

41 Difranza JR, Celebucki CC, Seo HG. A model for the efficient and effective enforcement of tobacco sales laws. Am J Public Health 1998;88:1100-1.

42 Cummings KM, Hyland A, Saunders-Martin T, et al. Evaluation of an enforcement program to reduce tobacco sales to minors. Am J Public Health $1998 ; 88: 932-6$.

\section{The Lighter Side}

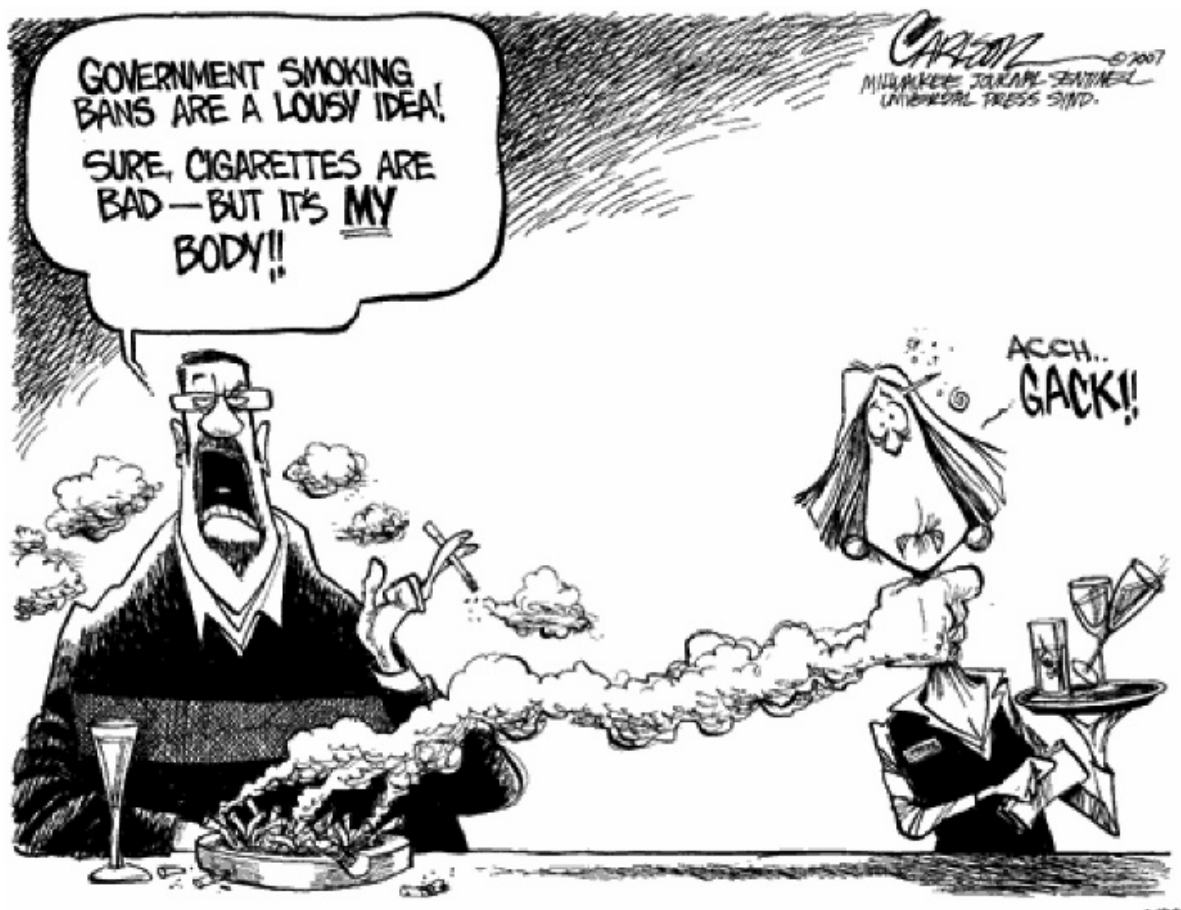

(C) Carlson, Milwaukee Journal Sentinel, Universal Press Syndicate. 